\title{
35 Years of Excellence Epilepsy Program, Western University
}

\author{
Jorge G. Burneo, David A. Steven
}

Can J Neurol Sci. 2012;39: Suppl 6: S1-S42

More than 35 years have passed since the futuristic vision of Warren Blume and John Girvin became a reality and a dedicated service for patients with epilepsy in the city of London, Ontario, started to operate. Little did they know, that the program would excel, growing to become one of the premier programs in Canada.

Since the official opening of the epilepsy unit, our program has provided care to thousands of patients from Southwestern Ontario and the rest of the country, including more than 2000 epilepsy surgeries.

Education and research have been important as well. From the prairies to the Atlantic Coast, from India to South America, leaders in research and clinical care have enlightened us with their presence during educational fellowships at University Hospital.

Research in electroencephalography, outcomes after surgery, neuroimaging, and basic science research have been the pillars to our growing knowledge in the different areas of epilepsy. A groundbreaking paper on temporal lobe epilepsy surgery published by one of our alumni, as well as innumerable manuscripts in prestigious medical journals, together with scientific presentations worldwide, have also allow to place our institution in an outstanding position, recognized by our Canadian and worldwide colleagues.

With the occasion of our 35th Anniversary, an academic day was organized in London, with participants from different corners of Canada and the world. A historical manuscript written by the founders of the program along with the content of the scientific presentations are presented in this special and one of a kind supplement.

Jorge G Burneo, MD, MSPH

David A Steven, $M D, M P H$

Co-Directors, Epilepsy Program, Western University

London, Ontario, Canada

Generously supported by

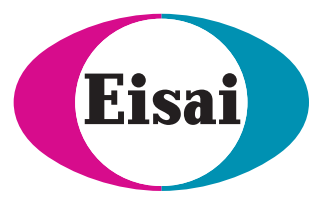

From the Epilepsy Program, Western University, London Health Sciences Center, London, Ontario, Canada.

Received January 26, 2012. Final Revisions Submitted August 7, 2012.

Correspondence to: Jorge G Burneo, Epilepsy Program, Western University, London Health Sciences Center, 339 Windermere Rd, B10-120, London, Ontario, N6A5A5, Canada. Email: jburneo2@uwo.ca. 